\title{
DESIGN UNIVERSAL: BANHEIROS INCLUSIVOS DE SHOPPINGS DE GRANDE PORTE
}

Eliete Auxiliadora Assunção Ourives, Dra Universidade Federal de Santa Catarina elieteourives@gmail.com

Alais Souza Ferreira

Especialização em Marketing Criativo UNIVALI

alais.ferreira@live.com
Luiz Fernando Gonçalves de Figueiredo, Dr. Universidade Federal de Santa Catarina Iffigueiredo2009@gmail.com

Milton Luiz Horn Vieira, Dr. Universidade Federal de Santa Catarina milton@cce.ufsc.br

Ludmilla Gonçalves de Figueiredo Graduada em Serviço Social - UFSC ludy.figueiredo@gmail.com

Resumo: Para projetar um espaço, ambiente ou objeto, seja a finalidade o design comercial, residencial ou universal, o designer necessita estudar e avaliar as funções práticas e estéticas. No caso do design universal que envolve pessoas com necessidades particulares, como mobilidade reduzida, cognição diferenciada, obesidade, que fazem parte de um grupo de população que merece atenção especial, a avaliação das funções práticas pelas normas técnicas (ABNT) e funções estéticas (cor, forma, textura, etc) são essenciais, principalmente tratando-se de um ambiente coletivo. Dessa forma, o objetivo geral deste trabalho foi avaliar três banheiros inclusivos adultos de três shoppings de grande porte, e com isso verificar, as suas conformidades, perante a norma ABNT NBR 9050/2015, como também em relação as suas funções estéticas. $O$ método de pesquisa deste artigo tem caráter qualitativo e exploratório. Os resultados demonstram que em uma análise geral, os banheiros encontram-se em conformidade com a norma ABNT NBR 9050/2015, e que o investimento no aspecto estético dos banheiros traz um diferencial em termos de conforto e aconchego. Ao final, este trabalho vem contribuir com a norma, o estabelecimento comercial analisado e principalmente com o usuário.

Palavras-chave: design universal, design de ambientes, banheiros inclusivo.

Abstract: To design a space, environment or object, whether for purpose the commercial, residential or universal design, the designer needs to study and assess the practical and aesthetic functions. In the case of universal design which involves people with particular needs, such as reduced mobility, cognition, obesity, which are part of a group of people who deserve special attention, the evaluation of practical functions for technical standards (ABNT) and aesthetic functions (color, shape, texture, etc.) are essential, especially in the case of a collective environment. Therefore, the overall objective of this work was to evaluate three bathrooms inclusive 
adult three large malls, and verify their conformity to the standard $A B N T$ NBR 9050/2015, as also their aesthetic functions. The method of research of this article has exploratory and qualitative character. The results show that in a general analysis, the bathrooms are in accordance with the standard ABNT NBR 9050/2015, and that investment in the aesthetic aspect of the toilets get a differential in terms of comfort and coziness. In the end, this work is to contribute with the standard, the retail store parsed and mainly with the user.

keywords: universal design, environments design, inclusive bathrooms.

\section{INTRODUÇÃO}

O design de ambientes é o resultado de um processo de criação que envolve a combinação de determinados elementos como formas, linhas, texturas, luzes, materiais e cores, visando atender três pontos fundamentais: a função, as necessidades objetivas e subjetivas dos usuários, e a estética através da utilização coerente e harmônica dos materiais e formas (GURGEL, 2014). Segundo a autora há design se houver a utilização desses elementos e dos seus princípios fundamentais como equilíbrio, ritmo, harmonia, unidade, escala e proporção, contraste, centro de interesse e variedade no processo criativo -, que são influenciados por aspectos como função, materiais, tecnologia e estilo.

Para projetar um espaço, ambiente ou objeto, seja a finalidade o design comercial, residencial ou universal, o designer de ambientes precisa estudar e saber aplicar esses elementos de design. No caso do design universal que envolve pessoas idosas, com necessidades físicas ou mentais e obesas - que fazem parte de um grupo que merece atenção especial - algumas considerações do projeto devem ser levadas em conta. Dentre elas é possível destacar, a escolha correta dos materiais e cores, acendimento da iluminação com sensor, mobiliários, portas, etc. Esses fatores são influenciados e determinados pelo tipo de ambiente a ser projetado e esse grupo de pessoas é assegurado pela Lei №1246/74 e norma técnica ABNT NBR 9050/2015 que garantem a eles acesso, conforto e fácil locomoção. No caso do banheiro inclusivo para estabelecimentos comerciais como Shoppings, restaurantes e lanchonetes, o código de obras e a norma técnica estabelecem dimensões mínimas destinadas a esse ambiente, assim como, o tipo de vaso sanitário, pia, mobiliário, acessórios, etc. $E$, elementos como cor, textura, iluminação, forma são fundamentais para tornar o ambiente acolhedor, com conforto, entre outros.

Dessa forma, a pesquisa tem como objetivo avaliar, as funções práticas, através das normas ABNT NBR 9050/2015 e as funções estéticas por meio da cor, textura, forma, etc, comparando três banheiros inclusivos de shoppings de grande porte.

\section{DESIGN UNIVERSAL}

$\mathrm{O}$ arquiteto Ron Mace usou a expressão Universal Design pela primeira vez nos Estados Unidos, articulando e influenciando projetos de arquitetura e design através de uma mudança de paradigmas (CAMBIAGHI, 2012). Essa mudança de paradigmas abrange o Inclusive Design e o Design for all (ALVARENGA, 2006). 
Design universal é a criação de ambientes/produtos que devem ser utilizados por um maior número possível de pessoas - incluindo crianças, idosos, pessoas com necessidades especiais e com tamanho ou formas atípicas -, promovendo a inclusão (CAMBIAGHI, 2012; NICKEL, 2012; STORY et al, 1998). O objetivo "é reduzir a distância funcional entre os elementos do espaço e as capacidades variadas das pessoas", possuindo alguns princípios que garantem ao usuário desfrutar do ambiente sem receber tratamento discriminatório (CAMBIAGHI, 2012, p. 81; GABRILLI, 2008).

O termo Design Inclusivo surgiu ao repensar o Design Universal e perceber que, devido à enorme diversidade de pessoas, é impossível que um único produto tenha solução acessível para todos, surgindo produtos com variações de altura, tamanho, entre outras (KEATES et. al.,2000). Design para todos é a produção de produtos com tecnologia de informação e comunicação que podem ser acessados por quase todos os usuários sem modificação, que se adaptam conforme as diferentes necessidades ou que possuam interfaces que podem ser acessadas pelo uso de tecnologia assistiva (EUROPE'S INFORMATION SOCIETY, 2010 apud NICKEL, 2012).

Tecnologia Assistiva (TA) são recursos e serviços que proporcionam ou ampliam habilidades funcionais de pessoas com necessidades especiais, promovendo vida independente e inclusão (BERSCH e SARTORETTO, 2014; BARBOSA FILHO, 2009). Para Bersch e Sartoretto (2014) recursos são todos ou qualquer item, equipamento ou parte dele, produto ou sistema fabricado em série ou sob medida, utilizados para aumentar, manter ou melhorar as capacidades funcionais das pessoas com necessidades especiais. Por exemplo, os banheiros inclusivos possuem alavanca ou sensor automático no acionamento da descarga da bacia sanitária e da torneira do lavatório, minimizando o esforço e torção das mãos para acioná-las.

"O ADA - American with Disabilities Act, lei que regula os direitos dos cidadãos com deficiência no EUA, [...] desenvolveu um universo de categorias para a área da" TA (NICKEL, 2012, p. 48), dentre elas a que será abordada neste artigo se refere aos "Projetos Arquitetônicos para Acessibilidade". Essa categoria abrange as adaptações estruturais e reformas em casa e/ou ambiente de trabalho, como as adaptações em banheiros para que eles se tornem inclusivos, entre outras que eliminam ou amenizam as barreiras físicas, facilitando a locomoção da pessoa com necessidades especiais. A norma NBR 9050 estabelece critérios e parâmetros técnicos a serem observados quanto aos ambientes em relação às condições de acessibilidade, proporcionando a utilização de maneira autônoma e segura do ambiente, mobiliário e elementos à maior quantidade possível de pessoas, independentemente de idade, estatura ou limitação de mobilidade ou percepção (ABNT, 2015). Dessa forma, as categorias de normas técnicas criadas pelo ADA, nos Estados unidos, juntamente com a NBR 9050 criada pela $A B N T$, no Brasil, "serviu de base para um estudo de adequação dos espaços às pessoas que têm algum tipo de" necessidades especiais (CAMBIAGHI, 2012, p. 61).

A norma NBR 9050 estabelece dimensões apropriadas para o acesso, alcance, manipulação e uso, independentemente do tamanho do corpo (obesos, anões, etc.), da postura ou mobilidade do usuário (pessoas em cadeira de rodas, bengalas, etc.). Por exemplo, os banheiros inclusivos que possuem dimensões adequadas para pessoas em cadeira de rodas ou as que estão com bebês em seus carrinhos. (GABRIELLI, 2008).

Portanto, conclui-se que os banheiros inclusivos devem ser planejados sob uma visão de design universal, levando em consideração as normas técnicas que dão suporte o mesmo ser desenvolvido para todos, e não apenas para pessoas com 
necessidades físicas. Dessa forma, a compreensão das necessidades humanas para a prática de um ambiente inclusivo (neste caso os banheiros), através da averiguação das normas técnicas, torna possível assegurar a criação de ambientes acessíveis. A seguir são apresentadas as funções do design de ambientes.

\section{FUNÇÕES DO DESIGN DE AMBIENTES}

Os aspectos essenciais das relações dos usuários com os produtos e ambientes são as suas funções, as quais se tornam perceptíveis no processo de uso e possibilitam a satisfação de certas necessidades, afirma Löbach (2001) e Munari (2008). Conforme os autores, são definidas três funções fundamentais que devem ser observadas pelo designer ao projetar: função prática, estética e simbólica. "Nesse sentido, propostas de atendimento a programas de necessidade devem levar em conta, além das necessidades básicas dos usuários, o impacto físico e psicológico causado pelo ambiente, bem como desempenho, segurança e satisfação" (CAMBIAGHI, 2012, p.43).

De acordo com Löbach (2001, p.58), "são funções práticas de produtos todos os aspectos fisiológicos do uso" que devem satisfazer plenamente as necessidades físicas do homem. Como exemplo, podemos citar os banheiros inclusivos, em que o vaso sanitário com abertura frontal que satisfazem tanto as necessidades de pessoas com deficiências físicas como obesas e idosas, contribuindo para o design universal.

A função estética é "um aspecto psicológico da percepção sensorial durante seu uso" (LÖBACH, 2001, p.60), ou seja, configurar os produtos de acordo com as experiências anteriores e percepção consciente, do homem, com as características estéticas (forma, cor, superfície, som, etc.). Além disso, a função estética promove a sensação de bem-estar, identificando o usuário com o produto e ambiente durante o processo do uso (LÖBACH, 2001), como os banheiros inclusivos, que pela cor neutra, a superfície antiderrapante e a forma do espaço contribuem para a segurança do bem estar de pessoas com necessidades visuais e físicas.

Para Ching e Binggeli (2006) a estética do design aborda a forma, proporção, escala, equilíbrio, harmonia, unidade e variedade, ritmo e ênfase, já Gurgel (2014) também considera o contraste e o centro de interesse, Gibbs (2005) complementa quanto às dimensões humanas, linha, plano, volume e repetição. A escala representa o tamanho real de alguma coisa em relação ao padrão reconhecido, enquanto a proporção se refere à relação entre as partes de uma composição, e estabelecem uma medida ideal de beleza e um conjunto coerente de relações que criam harmonia e equilíbrio (GIBBS, 2005; GURGEL, 2014). Sobre isso, Gurgel (2014) afirma que deve haver proporção no tamanho do mobiliário do ambiente, por exemplo, o assento tem que estar proporcional à bacia sanitária, etc.

O equilíbrio está associado ao modo que os elementos estão dispostos no ambiente, considera a área de circulação, as atividades realizadas e a iluminação. Por exemplo, as medidas do ambiente têm que estar proporcional ao tamanho da cadeira de rodas do portador de necessidades físicas, possuindo área de circulação para a mesma realizar as atividades. Os autores Ching \& Binggeli (2006) e Gurgel (2014), descrevem três tipos de equilíbrios visuais: simétrico, radial e assimétrico.

Já a harmonia é a combinação dos elementos - tamanhos, cores, formas, texturas, materiais, iluminação, etc. -, e a maneira como estão organizados no ambiente. E, o ritmo é a relação dos elementos podendo incluir intervalos regulares, objetos ou formas idênticas em uma trajetória retilínea, ou uma série de elementos 
arquitetônicos repetidos - tais como colunas, pilares, idênticos ou a repetição de pequenos detalhes, criando dinamismo na composição. (GURGEL, 2014).

Segundo Gurgel (2014), o contraste se consegue pela cor, luz, texturas, tamanhos, formas e posicionamento, sendo necessário haver a predominância de um desses elementos quando dispostos juntos no ambiente. Os centros de interesse podem ser vários elementos, no caso dos banheiros inclusivos é o espelho, que é um recurso compositivo que domina os elementos dentro do ambiente (GIBBS, 2005).

A linha é uma sequência de pontos que pode significar movimento, direção, crescimento, peso, caráter visual, comprimento, espessura e continuidade. A linha horizontal da a sensação de ampliação do ambiente e pode representar estabilidade e repouso, relaxante e informal, principalmente quando longa. (GURGEL, 2014, CHING e BINGGELI, 2006). Já a linha vertical sugere altura e imponência, é dura (rígida) e formal, transmitindo a sensação de formalidade e altivez (GURGEL, 2014).

As formas planas, geométricas, bi ou tridimensional e o contorno plano que podem ser utilizadas em pisos, paredes, tetos, servem para delimitar e definir o volume tridimensional do espaço, assim como, as características dos materiais utilizados em sua superfície. (CHING e BINGGELI, 2006).

A textura é a qualidade das superfícies dos materiais. O tipo de textura utilizada deve atender às necessidades das atividades que serão desenvolvidas nos ambientes, em relação aos aspectos estéticos e funcionais, como segurança, conforto, higienização, etc. (CHING e BINGGELI, 2006). Por exemplo, o piso dos banheiros inclusivos que precisam ser antiderrapantes, possuindo uma textura áspera.

A iluminação é proporcionar boas condições de visão associadas à visibilidade, à segurança e à orientação dentro de determinado espaço e de ambientação. Portanto, possui uma finalidade associada à função prática e estética do ambiente. (CHING e BINGGELI, 2006; GURGEL, 2014).

A cor influencia o ser humano tanto psicologicamente quanto fisiologicamente. Ela é o resultado da reflexão de seu matiz predominante e da absorção das outras cores da luz que a iluminam. (CHING e BINGGELI, 2006). Dessa forma, observa-se a importância dos elementos de design referenciados anteriormente para as funções prática, estética e simbólica nos ambientes como os banheiros inclusivos. A seguir será abordado sobre os procedimentos metodológicos.

\section{PROCEDIMENTOS METODOLÓGICOS}

Esta pesquisa é classificada quanto sua finalidade como básica estratégica que é voltada "à aquisição de novos conhecimentos direcionados a amplas áreas" para a solução de problemas práticos. Pelos seus objetivos como exploratória por proporcionar "mais familiaridade com o problema, com vistas a torná-lo mais explícito ou a construir hipóteses". (GIL, 2010, p.27).

Por sua natureza como qualitativa que busca "analisar e interpretar aspectos mais profundos, descrevendo a complexidade do comportamento humano" e "fornece análise mais detalhada sobre as investigações" (MARCONI E LAKATOS, 2011, p. 269). Por seus procedimentos técnicos como: pesquisa bibliográfica que "é elaborada com base em material já publicado" (GIL, 2010, p.29); e observação que é uma técnica de coleta de dados usada para conseguir informações e que emprega os sentidos na obtenção de determinados aspectos da realidade (MARCONI E LAKATOS, 2011). 
Figura 1. Processo metodológico
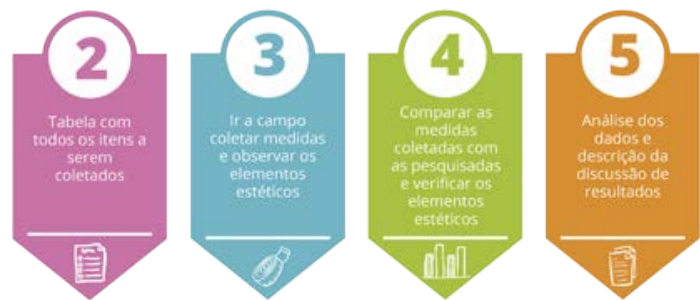

Fonte: Elaborado pelos autores.

$\mathrm{Na}$ etapa um pesquisou-se quais as medidas e elementos deveriam ser observados. Em seguida, foi desenvolvido uma tabela com esses itens. A etapa três foi o momento de ir a campo nos shoppings coletar as medidas e observar os elementos estéticos. Em um quarto momento as medidas dos banheiros foram comparadas com as medidas da norma, e verificou-se quais elementos estéticos fazem parte de cada ambiente. $\mathrm{Na}$ etapa cinco foi realizada a análise dos dados e descrita à discussão dos resultados (vide figura 1 ).

Por motivos legislativos a identidade dos shoppings será mantida em anonimato, por isso classificou-se os banheiros em B1, B2 e B3 (vide figuras 2, 3 e 4).

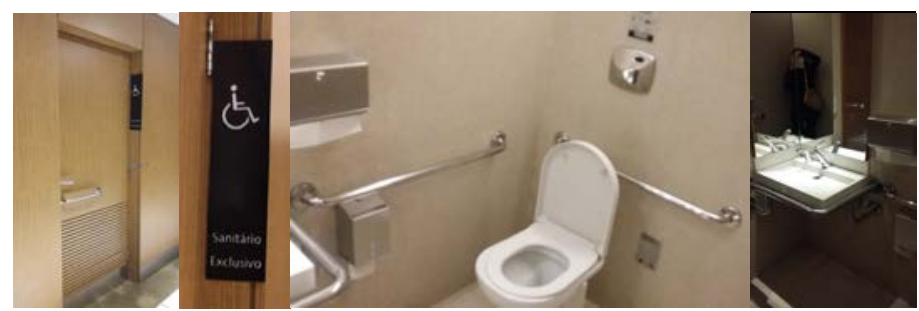

Figura 2. Banheiro do shopping (B1)

Fonte: Elaborado pelos autores.

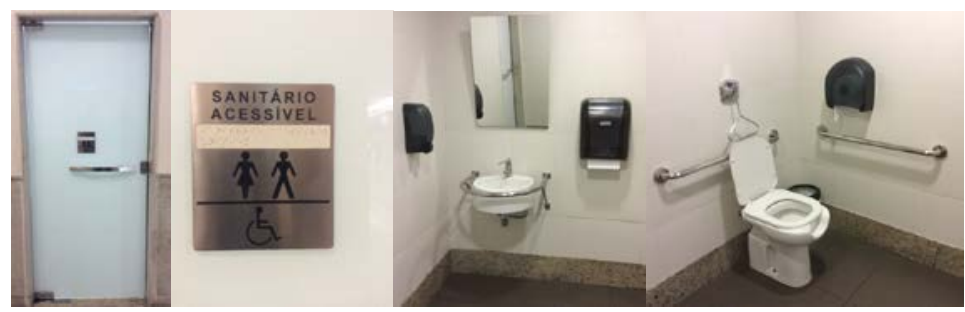

Figura 3. Banheiro do shopping (B2)

Fonte: Elaborado pelos autores.

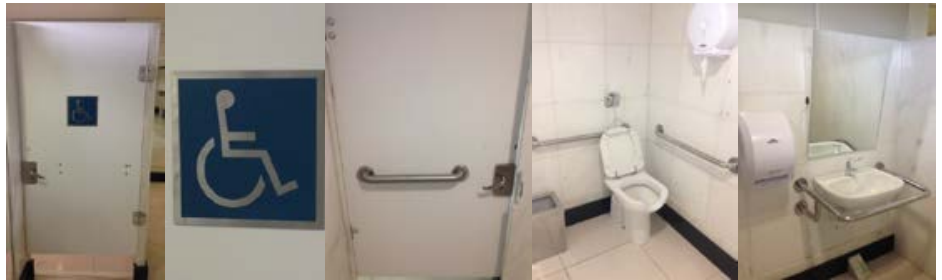

Figura 4. Banheiro do shopping (B3)

Fonte: Elaborado pelos autores.

O estudo foi realizado em três shoppings de grande porte, onde se analisou um banheiro inclusivo de cada shopping. Além disso, a discussão dos resultados foi divida em duas etapas: na primeira foi realizada uma análise de comparação desses banheiros conforme a norma da ABNT (Associação Brasileira de Normas Técnicas) NBR (Normas Brasileiras Regulamentadas) 9050/2015; e na segunda foram identificadas e 
comparadas as funções estéticas do design. A seguir será realizada a discussão dos resultados obtidos.

\section{DISCUSSÃO DOS RESULTADOS}

A discussão dos resultados, conforme os procedimentos metodológicos, foi dividida em duas partes: a primeira relacionada à função prática, comparando e verificando se os banheiros estão adequados a norma NBR 9050/2015; e a segunda se refere à identificação e comparação das funções estéticas do design no ambiente.

\subsection{Função prática do ambiente conforme a norma técnica ABNT NBR 9050/2015}

A função prática dos banheiros inclusivos foi verificada conforme a norma técnica, a partir dos aspectos (vide figura 5):
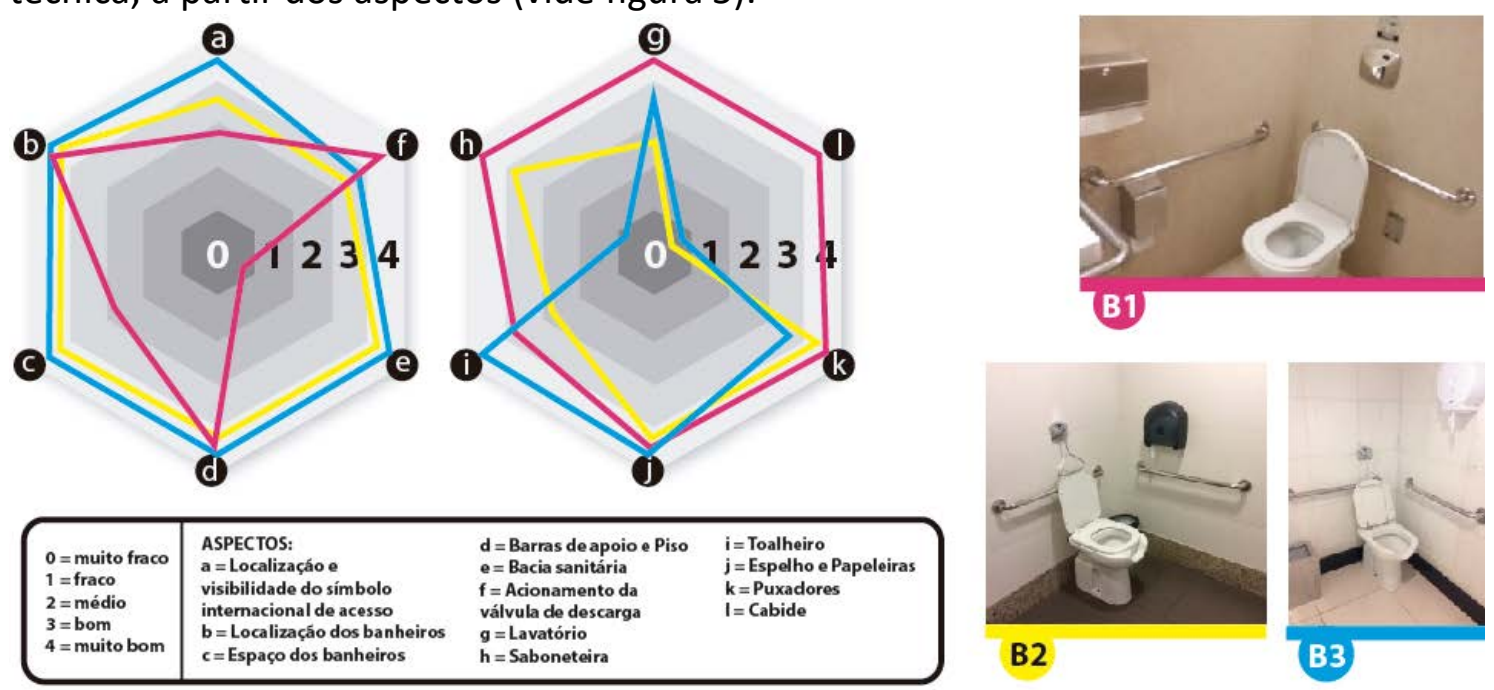

Figura 5. Análise da Função Prática.

Fonte: Elaborado pelos autores.

a) Localização e visibilidade do símbolo internacional de acesso: no B2 e B3 está disposto no centro, já no B1 está no lado direito. Apenas o símbolo do B3 possui boa visibilidade e está exatamente igual ao padrão informado na norma (pictograma branco sobre fundo azul). O símbolo de B1 (pictograma branco sobre fundo preto) está conforme o padrão, mas não possui o formato quadrado. Já o B2 está com o símbolo fora do padrão por possuir apenas o pictograma sem a delimitação do quadrado e com cores diferentes. Além disso, a norma não informa a respeito de colocar uma denominação juntamente com o símbolo, mas o B1 acrescenta a palavra "Banheiro Exclusivo", e o B2 acrescenta "Sanitário Acessível" e dois símbolos que indicam a utilização do banheiro por pessoas sem necessidades, tornando-o acessível para todos.

b) Localização dos banheiros: B1 e B2 são banheiros com entrada independente localizados ao lado dos demais, já o B3 é um box que se encontra dentro dos demais banheiros deixando-o mais inclusivo, mesmo que ambas localizações estejam corretas.

c) Espaço dos banheiros: é retangular e as medidas estão padronizadas. B1 possui espaço apenas na lateral como área de transferência para a bacia sanitária, já B2 e B3 além do espaço lateral, possui também área frontal e diagonal.

d) Barras de apoio e piso: em ambos os banheiros as barras de apoio estão localizadas na lateral e fundo da bacia sanitária, e suas medidas estão padronizadas conforme a norma. Porém, de acordo com a norma teria que ter uma barra vertical na 
parede lateral da bacia sanitária, mas não possui em nenhum banheiro, porque possivelmente os mesmos foram construídos/adaptados antes da atualização da norma ABNT NBR 9050/2015 onde está inserida essa recomendação. As barras de apoio do lavatório, em todos os banheiros, se encontram na parte da frente e laterais, sua localização coincide com a apresentada na norma e suas medidas estão padronizadas. Todos os banheiros possuem pisos lisos, neutros, regulares, firmes, estáveis, antiderrapantes e com ralos fora da área de circulação do cadeirante.

e) Bacia sanitária: As medidas referentes à altura da bacia sanitária, com assento e sem assento, estão padronizadas em todos os banheiros. A forma da bacia sanitária do B2 e B3 possui curvatura na parte frontal para circular o ar, para que pessoas acima do peso não entalem. Já o B1 possui formato tradicional.

f) Acionamento da válvula de descarga: o B1 possui acionamento de descarga automático por sensores eletrônicos, já o B2 e B3 possuem acionamento manual do tipo alavanca. Em todos os banheiros a altura da descarga em relação ao piso está padronizada conforme a norma.

g) Lavatório: todos estão localizados em locais que não interferem na locomoção, seus formatos estão de acordo com a norma e suas medidas estão padronizadas, com exceção do B2 em que a largura do lavatório está fora do padrão. A torneira do B1 é automatizada por sensores eletrônicos, já o B2 e B3 possuem acionamento manual do tipo alavanca.

h) Saboneteira: o B1 possui saboneteira com acionamento automatizado por sensores eletrônicos, está localizado junto à torneira e está dentro da faixa de alcance. O B2 possui saboneteira com acionamento manual e está localizado na parede lateral. E o B3 não possui saboneteira, dificultando a mobilidade do cadeirante.

i) Toalheiro: O toalheiro do B1 é manual e B2 é por alavanca, já o do B3 possui sensores eletrônicos, ambos estão localizados ao lado do lavatório e dentro da faixa de alcance conforme a norma.

j) Espelho e papeleiras: as medidas e localização desses objetos estão padronizados em todos os banheiros. Porém, em B1 o espelho se estende até o teto e no B2 e B3 possui inclinação.

k) Puxadores: Todos os banheiros possuem puxadores horizontais na porta em ambos os lados, com exceção do B3 que possui apenas na parte interna e mesmo assim está padronizado de acordo com a norma. Além disso, as medidas e formatos de todos estão padronizados.

I) Cabide: Apenas o B1 possui cabide, que possui localização correta e está dentro da faixa de alcance conforme a norma.

\subsection{Contribuição das funções estéticas do design para os banheiros inclusivos}

As funções estéticas do design foram identificadas e analisadas conforme a fundamentação teórica dos autores Ching e Binggeli (2006), Gurgel (2014) e Gibbs (2005) nos três banheiros, vide figura 6. 

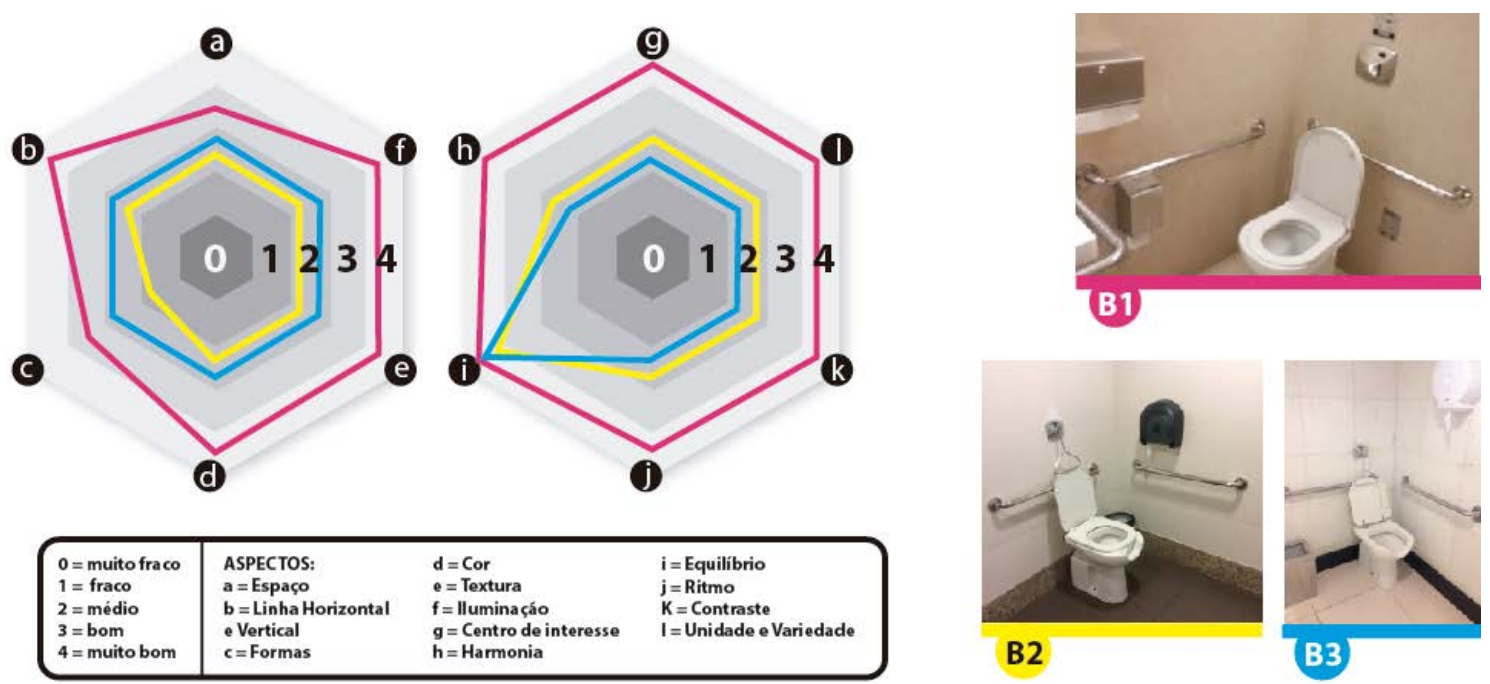

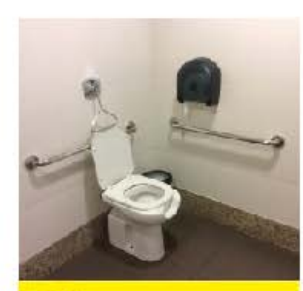

B2

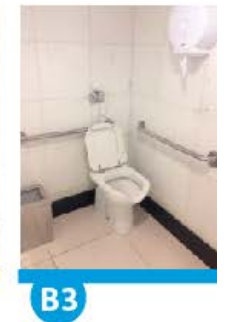

Figura 6. Análise da Função Estética.

Fonte: Elaborado pelos autores.

a) Espaço: O B1 em relação aos demais possui apenas um espaço de circulação que é suficiente para transferência do cadeirante a bacia sanitária, o B2 e B3 oferecem mais opções de espaço de circulação. O B1 possui cores mais escuras nas paredes (marrom claro), em relação ao B2 e B3 (paredes brancas), modificando a percepção da proporção entre largura e o comprimento do ambiente. O B1 se preocupou com todos os elementos (espelho, louças, barras, lixeira, iluminação e acessórios) para que formasse uma composição agradável e diferenciada. O B1 utilizou a proporção e escala do espelho para dar interesse não atrapalhando a funcionalidade, diferentemente do B2 e B3 que seguiu os padrões da norma.

b) Linha Horizontal e Vertical: B1 por não apresentar linhas horizontais e verticais nas paredes fornece sensação de aconchego, entretanto B2 e B3 possuem muitas linhas horizontais e verticais nas paredes formadas pelo rejunte dos azulejos não transmitindo a mesma sensação. B1, B2 e B3 possuem uma linha horizontal formada pela faixa de alcance dos acessórios sanitários, porém B1 possui essa linha com comprimento menor evidenciando ainda mais a sensação de aconchego.

c) Formas: A forma geométrica B1, B2 e B3 é retangular, o contorno é retilíneo, simples e estável, e o volume é tridimensional. Porém, B1 possui volume tridimensional menor que o B2 (maior volume) e o B3 (volume intermediário), por este motivo o B1 apresenta espaço suficiente para o cadeirante com maior sensação de privacidade em relação aos outros.

d) Cor: A cor é neutra em B1, B2 e B3 deixando o ambiente com uma atmosfera refinada e elegante, neutralizando o espaço compositivo. Em B1 prevalece os tons de marrom, em B2 e B3 prevalece a cor branca. A cor marrom transmite sensação de conforto físico, segurança, simplicidade, calma. Já a cor branca transmite a sensação de paz, pureza, limpeza, dá ideia de maior espaço, e em excesso, pode dar a impressão de frieza, vazio e impessoalidade. Observa-se que o excesso de cor branco utilizado no B2 e B3 promoveu essa sensação de vazio e impessoalidade, já o B1 intercalou vários tons de marrom sem prevalecer um tom só proporcionando aconchego.

e) Textura: Em B1, B2 e B3 a textura das paredes e teto são táteis, lisas e opacas. O piso de todos é antiderrapante, possuindo uma textura áspera. As paredes 
do B1 possuem uma textura lisa contínua proporcionando bem-estar, diferentemente do B2 e B3 que possuem azulejo com rejunte.

f) Iluminação: A luz em B1, B2 e B3 é artificial. Em B1 possui uma iluminação de tarefa no teto acima do lavatório com facho difuso e iluminação de destaque no teto em uma das paredes com um facho indireto, em que a luz incide sobre a parede por "rebatimento" o ambiente é iluminado, e wall-washing, provocando um efeito de atmosfera aconchegante com ponto de interesse na parede, que em conjunto com a cor do ambiente proporciona tranquilidade. Em B2 e B3 possui iluminação geral com lâmpadas centralizadas embutidas no teto. Em todos os banheiros é possível ver o espaço como um todo, permitindo caminhar e circular sem dificuldades.

g) Centro de interesse: $O$ centro de interesse estabelece dominância dos elementos dentro do ambiente, e em B1, B2 e B3 é o espelho. O B1 deu mais destaque para o centro de interesse com uma estética mais contemporânea estendendo-o até o teto e para a lateral, além de utilizar um lavatório maior. E o B2 e B3 optaram por um modelo mais tradicional.

h) Harmonia: Existe harmonia no ambiente de B1, B2 e B3 em relação a composição do todo, que está em consonância e combinação com os elementos (tamanho, cores e valores, formas, texturas, materiais, iluminação). Porém, B1 conseguiu aplicar a cor juntamente com a iluminação criando uma temática harmônica no ambiente, diferentemente de B2 e B3.

i) Equilíbrio: O equilíbrio é assimétrico caracterizado pelo uso de objetos diferentes, mas que possuem um mesmo peso visual, gerando a sensação de movimento e tornando o ambiente dinâmico, informal e espontâneo.

j) Ritmo: O ritmo em B1, B2 e B3 ajuda dar unidade ao ambiente por meio de uma correlação dos elementos arquitetônicos. Em B1 está presente na iluminação da parede que junto com a cor proporciona contraste, gerando um visual mais destacado. Em B2 e B3 está presente na repetição dos azulejos nas paredes e das lajotas no piso.

k) Contraste: Existe contraste de luz e cor entre as paredes e piso em B2. Em B3 o contraste está entre o rodapé preto e o piso e parede branca. Em B1 existe um pequeno contraste entre as cores das paredes e porta, porém o maior contraste está na iluminação de destaque entre o teto e parede.

I) Unidade e variedade: Em B2 e B3 possui unidade já que no geral o ambiente é todo branco apenas com o piso do B2 e o rodapé do B3 em preto e não explorou a variedade, mesmo com o acréscimo mínimo do preto no rodapé e piso o ambiente ficou monótono. Em B1 possui unidade já que seguiu o mesmo estilo no ambiente todo juntamente com a variedade de tons de marrom (parede, piso, porta) rompendo a monotonia do ambiente, o que não se verifica em B2 e B3.

A seguir será apresentado a conclusão dos resultados obtidos pelas funções práticas (normas técnicas) e estéticas (princípios do design).

\section{CONCLUSÃO}

Os resultados demonstram a importância do estudo de design inclusivo, função prática e estética do design nos banheiros dos shoppings de grande porte. Em relação à função prática, comparando os banheiros pela norma (vide figura 5), nos aspectos: localização dos banheiros, barras de apoio, piso, espelho e papeleiras todos estão adequados; espaço dos banheiros e bacia sanitária o B2 e B3 são mais adequados em relação a B1; acionamento da válvula de descarga, lavatório, saboneteira e cabide B1 é 
- mais adequado em relação ao B2 e B3; localização e visibilidade do símbolo internacional de acesso e toalheiro $B 3$ é o mais adequado em relação a B1 e B2; puxadores o B1 e B2 estão mais adequados em relação ao B3.

Porém, a norma não estabelece tamanho padrão mínimo e máximo para o símbolo internacional de acesso, o que compromete a visibilidade, e não determina a nomenclatura adequada para ser colocada juntamente com o símbolo, comprometendo a padronização. A norma recomenda ducha higiênica ao lado da bacia sanitária, mas nenhum banheiro aplicou a recomendação. Em relação a localização dos banheiros, B1 e B2 optaram por tornar os banheiros inclusivos individuais, separandoos dos demais, já o B3 planejou o modo box, inserindo-o no banheiro coletivo, o que permite a socialização das pessoas.

A identificação dos aspectos da função estética do design proporcionou o entendimento do projeto visual do ambiente inclusivo em termos de composição, visando à percepção, inspiração, criatividade e inovação do designer de ambientes que o planejou. As cores neutras e pisos sem estampas utilizados nos três banheiros proporciona sensação de segurança, e segue a recomendação da norma - que sugere evitar a utilização de padronagem na superfície do piso, que possa causar a impressão de tridimensionalidade.

Em relação à função estética, no aspecto equilíbrio todos os banheiros estão adequados, mas nos aspectos espaço, linhas, formas, cor, textura, iluminação, centro de interesse, harmonia, ritmo, contraste, unidade e variedade B1 está mais adequado que B2 e B3. Com isso, é possível concluir que B1 é mais adequado, pois ao planejar a iluminação - entre a parede e o teto - juntamente com os aspectos citados e todos os objetos (por exemplo, o espelho), conseguiu fornecer um ambiente aconchegante e com conforto físico. Se a função estética fosse mais planejada no B2 e B3 como foi em B1, eles transmitiriam a mesma sensação.

Conclui-se que de forma geral, em relação à função prática que todos os banheiros são acessíveis e estão padronizados conforme a norma ABNT NBR $9050 / 2015$. Sugere-se para trabalhos futuros, a adequação de alguns elementos conforme citado anteriormente, criando um ambiente diferenciado e mais inclusivo no B2 e B3. Como também, que esta pesquisa seja aplicada a outros estabelecimentos comerciais semelhantes, a fim de verificar a acessibilidade dos mesmos.

\section{REFERÊNCIAS}

ABNT, Associação Brasileira de Normas Técnicas. Norma Brasileira Regulamentar: NBR 9050:2015. 2015. Disponível em: <http://www.ufpb.br/cia/contents/manuais/abntnbr9050-edicao-2015.pdf>. Acesso em: 03 Jun. 2016.

ALVARENGA, Flavia Bonilha. Uma abordagem metodológica para o projeto de produtos inclusivos. Campinas, 2006. Tese (Doutorado em Engenharia Mecânica) Universidade Estadual de Campinas, Faculdade de Engenharia Mecânica, Programa de Pós-graduação em Engenharia Mecânica. Campinas, 2006.

BARBOSA FILHO, A. N. Projeto e desenvolvimento de produtos. São Paulo: Atlas, 2009.

BERSCH, Rita; SARTORETTO, Mara Lúcia. Tecnologia Assistiva. 2014, não paginado. Disponível em: <http://www.assistiva.com.br/tassistiva.html>. Acesso em: 09 Mai. 2016. 
BRASIL. Decreto n. 5.296 de 2 de dezembro de 2004. 2004. Disponível em: <http://cedipod.org.br/Dec.5296.htm>. Acesso em: 09 Mai. 2016.

CÂMARA MUNICIPAL DE FLORIANÓPOLIS. Lei no 1246/74: institui código de obras e edificações do município de Florianópolis. 1974. Disponível em: < https://www.google.com.br/url?sa=t\&rct=j\&q=\&esrc=s\&source=web\&cd=1\&cad=rja\& uact=8\&ved=0ahUKEwjK6rXKrqnOAhVCDpAKHUu4BFoQFggcMAA\&url=http\%3A\%2F\% 2Fsistemas.sc.gov.br\%2Fcmf\%2Fpesquisa\%2Fdocs\%2F1974\%2FLPMF\%2Flei1246_74.d oc\&usg=AFQjCNHd8aizOkF_8lzgs_nor350YqbnYg\&sig2=x5yOduowrOoDZzKlyy017Q\&bv m=bv.128617741,d.Y2I>. Acesso em: 09 Mai. 2016.

CAMBIAGHI, Silvana. Desenho universal: métodos e técnicas para arquitetos e urbanistas. 3. Ed. São Paulo: Editora Senac São Paulo, 2012.

CHING, Francis D.K.; BINGGELI, Corky. Arquitetura de Interiores Ilustrada. 2. ed. Porto Alegre: Bookman, 2006.

GABRILLI, Mara. Desenho universal: um conceito para todos. 2008. Disponível em: <http://www.vereadoramaragabrilli.com.br/files/universal_web.pdf >. Acesso em: 15 Ago. 2016.

GIBBS, Jenny. Interior Design. London: Laurence King, 2005.

GIL, A. C. Como elaborar projetos de pesquisa. 4. ed. São Paulo: Atlas, 2010.

GURGEL, Miriam. Projetando Espaços: Guia de Arquitetura de interiores para áreas comerciais. 5. ed. São Paulo: Senac, 2014.

GUBERT, Marjorie Lemos. Design de Interiores: a padronagem como elemento compositivo no ambiente contemporâneo. Porto Alegre, 2011. Dissertação (Mestrado em Design) - Universidade Federal do Rio Grande do Sul, Programa de Pós-graduação em Design. Porto Alegre, 2011.

KEATES, S.; CLARKSON, P. J.; HARRISON, L. \& ROBINSON, P. Towards a practical inclusive design approach. Proceedings of ACM Conf. on Universal Usability, 2000. Disponívelem: <http://dl.acm.org/citation.cfm?id=355471>. Acesso em: 06 Mai. 2016. LÖBACH, Bernd. Design Industrial: bases para a configuração dos produtos industriais. São Paulo: Ed. Blucher, 2001.

MUNARI, B. Das coisas nascem coisas. 2. ed. São Paulo, SP: Martins Fontes, 2008.

MARCONI, M. A.; LAKATOS, E. M. Metodologia científica. São Paulo: Atlas, 2011.

NICKEL, Elton Moura. Sistematização da implementação de tecnologia assistiva para o contexto educacional. Florianópolis, 2012. Tese (Doutorado em Engenharia de Produção) - Universidade Federal de Santa Catarina, Centro Tecnológico, Programa de Pós-graduação em Engenharia de Produção. Florianópolis, 2012.

STORY, M.; MUELLER, J. \& MACE, R. The Universal Design file: designing for people of all ages and abilities. Raleigh North Carolina: NC State University, The Center for Universal Design, 1998, não paginado. Disponível em: <http://www.udeduca tion.org/resources/63.html\#top>. Acesso em: 06 Mai. 2016. 